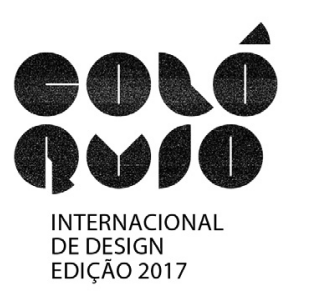

\title{
Abordagem Sistêmica associada à gamificação como uma ferramenta de prototipagem de serviços
}

\author{
Alais Souza Ferreira; \\ Luiz Fernando Gonçalves de Figueiredo; \\ Eliete Auxiliadora Assunção Ourives.
}

resumo:

O design não se restringi apenas a elaboração e prestação de um serviço, uma vez que este vem ampliando seu campo de atuação de maneira mais estratégica. Para este novo olhar, o foco é transferido dos objetos para o estudo global dos sistemas considerando todos os processos envolvidos. A gamificação surge como ferramenta para auxiliar na compreensão deste estudo, tornando-o mais dinâmico, divertido e envolvente. A gestão do design busca promover um melhor gerenciamento de pessoas, projetos, processos e procedimentos relacionados com os serviços, ambientes e experiências, além de visar uma abordagem holística. Inserido neste contexto, está o design de serviço que ajuda a inovar, criar novos, ou aperfeiçoar serviços, tornando-os mais úteis, usáveis e desejáveis aos clientes, eficiente e eficaz para as organizações. No Município de Chapadão do Lageado, os estabelecimentos locais precisam obedecer as normas de higiene e segurança, separar e descartar corretamente os resíduos e implantar sistemas de identidade visual. Diante do expostos, surge o questionamento: como a abordagem sistêmica, a gamificação e a prototipagem de serviços podem estar relacionadas com os empreendimentos dos microempreendedores? Desta forma, a pesquisa objetiva identificar a relação entre abordagem sistêmica associada à gamificação e prototipagem de serviços dos microempreendedores. Porém, é relevante esclarecer que este artigo busca discutir essas relações com o apoio de dados secundários, constituídos de referências bibliográficas e documentos, com a finalidade de levantar reflexões sobre o assunto e fornecer base teórica para uma pesquisa acadêmica científica. Portanto, a pesquisa classifica-se como qualitativa, exploratória e descritiva. Os resultados apontam que a gestão de design - com abordagem sistêmica baseada na produção, serviços e usuário - dos empreendimentos de microempreendedores pode ser aprimorada, por ser uma área em amplo desenvolvimento e possuir grande flexibilidade de oportunidades de negócios como saneamentos, capacitação, atendimento ao cliente, entre outras. Além disso, este artigo contribui com uma discussão teórica sobre a abordagem sistêmica relacionada com a gamificação e a prototipagem de serviços, que servirá de base para o desenvolvimento de uma pesquisa acadêmica científica, além de contribuir com uma reflexão para novas pesquisas nesta área.

palavras-chave:

gestão de design, abordagem sistêmica, prototipagem de serviços, gamificação. 


\section{Introdução}

Em tempos de transformações, o Design vem ampliando seu campo de atuação de maneira mais estratégica, não se restringindo somente a elaboração e produção de um produto ou prestação de um serviço. Para este novo olhar do design pôde-se entender o processo como sendo uma abordagem sistêmica, ou seja, o estudo global dos sistemas de forma a envolver todas as suas interdependências, pois cada um dos elementos, ao serem reunidos para construir uma unidade funcional maior, desenvolvem qualidades que não se encontram em seus componentes isolados (BERTALANFFY, 2008).

Com isso, a gamificação surge como uma ferramenta para auxiliar na compreensão deste estudo global dos sistemas e como eles se inter-relacionam, tornando essas "atividades corriqueiras mais dinâmicas, divertidas e envolventes, através da implementação de elementos de jogos" (AMÉRICO, NAVARI e BELDA, 2014, p.808). Os autores Vianna et al (2013), Cohen (2011), Navarro (2013), McGonigal (2012) e Quadros (2015) partilham da mesma visão e complementam que a gamificação auxilia na capacitação e treinamento dos profissionais.

Dessa forma, a gestão do design busca promover um melhor gerenciamento de pessoas, projetos, processos e procedimentos que estão relacionados com os produtos ou serviços, ambientes e experiências que fazem parte da sociedade (BEST, 2012). Além disso, ela também vem se preocupando com a sua qualidade, visando uma abordagem mais holística e integrando a produção de bens, serviços, marketing, recursos humanos, meio ambiente, qualidade de vida, ética e responsabilidade social, com uma visão técnica e estratégica (MOZOTA, 2001; MARSHALL JUNIOR, ROCHA e MOTA, 2012).

Inserido neste contexto, encontra-se o design de serviço que ajuda a inovar, criar novos, ou aperfeiçoar serviços, tornando-os mais úteis, usáveis e desejáveis para os clientes, eficiente e eficaz para as organizações. É um novo campo holístico, multidisciplinar e integrativo, por conectar as áreas de marketing, design, gestão de empresa e pesquisa de cliente (MORITZ, 2005).

Neste cenário estão os serviços prestados por microempreendedores, entre eles está o turismo rural na agricultura familiar (TRAF) que é o turismo praticado no meio rural. Em 1999, técnicos e agricultores perceberam a oportunidade da prestação de serviços de alimentação e hotelaria no meio rural, já que nos municípios não havia restaurantes e hotéis, formando o agroturismo. (TURNES e GUZZATTI, 2015).

A pesquisa de Lauro, Hoffmann e Figueiredo (2012) identificou que, no Município de Chapadão do Lageado, os estabelecimentos locais de alimentos precisam: utilizar produtos orgânicos locais; obedecer as normas de higiene e segurança da Agência Nacional de Vigilância Sanitária (ANVISA); separar e descartar corretamente os resíduos; implantar sistemas de identidade visual no ambiente, em impressos, no comportamento, etc. E também, identificaram oportunidades para esses empreendimentos como: vender os produtos; colocar serviço de restaurante; investir em divulgação local para a compra de matérias-primas e venda de produtos; e divulgar os passeios para conhecer os produtores locais.

Diante do exposto, questiona-se: como a abordagem sistêmica, a gamificação e a prototipagem de serviços podem estar relacionadas com os empreendimentos dos microempreendedores? Desta forma, o trabalho objetiva identificar a relação entre abordagem sistêmica associada à gamificação e prototipagem de serviços dos microempreendedores, para isto é necessário conceituar abordagem sistêmica, gamificação, prototipagem de serviços e abordar sobre as características dos serviços de microempreendedores; para em seguida compreender como se dá a relação entre estas áreas; e então apontar as conclusões que surgiram durante este processo. A partir disso, é relevante esclarecer que este artigo busca discutir essas relações com o apoio de dados secundários, constituídos de referências bibliográficas e documentos, com a finalidade de levantar reflexões sobre o assunto e fornecer base teórica para uma pesquisa acadêmica científica. Portanto, pelos procedimentos metodológicos a pesquisa classifica-se como qualitativa, exploratória e descritiva (CRESWELL, 2016; GIL, 2010; VIRGILLITO, 2010), uma vez que visa levantar discussões sobre o tema abordado.

Este trabalho justifica-se devido ao fato de que gamificação tem feito parte de muitas áreas de conhecimento, principalmente das relacionadas com a inovação. Com isso, Quadros (2015) informa que a comunidade acadêmica passou a investigar os fenômenos envolvidos nas atividades que envolvem desafios e elementos de games em dinâmicas empresariais. 
Por isso, busca-se estudar a abordagem sistêmica associada à gamificação voltada para a prototipagem de serviços dos microempreendedores (agricultores familiares), uma vez que o Núcleo de Abordagem Sistêmica do Design (NASDESIGN) já vem realizando pesquisas nessa área. Conforme Figueiredo et al (2009, p.1511), em 2002 eles fizeram "um convenio de parceria entre o governo do estado de Santa Catarina (Brasil), através do Centro de Estudos de Safras e Mercados (EPAGRI) vinculado a Secretaria de Estado da Agricultura e Política Rural do Estado de Santa Catarina" para o desenvolvimento de projetos relacionados a valorização de produtos e serviços da agricultura familiar. $\mathrm{O}$ autor continua informando que esses projetos têm gerado impactos positivos, como: o reconhecimento da importância do design pelos produtores rurais; a geração e melhoria da renda; novas oportunidades de desenvolvimento e crescimento no local de origem; reconhecimento de órgãos de fomento e apoio; e a ativa participação das comunidades, aportando ideias e discutindo as propostas, com uma postura considerada proativa e altamente positiva. Portanto, "o design pode ser utilizado como elemento-chave para o desenvolvimento de casos de inovação social", pois as iniciativas desenvolvidas pelo NASDESIGN mostram que as ações de design ampliam a visibilidade dos implicados com as soluções, e auxiliam numa melhor organização interna entre os integrantes das comunidades favorecidas. Este enfoque nos fatores sociais equilibra os fatores econômicos e ambientais. (FIGUEIREDO et al, 2009, p.1515)

Por fim, este trabalho vem contribuir com uma discussão teórica sobre a abordagem sistêmica associada à gamificação e a prototipagem de serviços de microempreendedores, que servirá de base para o desenvolvimento de uma pesquisa acadêmica científica. além de contribuir com uma reflexão para novas pesquisas nesta área. A próxima seção apresenta os procedimentos metodológicos da pesquisa mais detalhadamente.

\section{Procedimentos Metodológicos}

Esta seção apresenta os procedimentos metodológicos utilizados para nortear esta pesquisa e atingir os objetivos aqui especificados. Portanto, divide-se em três etapas (vide imagem 1): 1) Fazer levantamento bibliográfico de forma exploratória, em livros e base de dados eletrônicos, sobre abordagem sistemica, gamificação, gestão de design, design de serviço, microempreendedores, economia criativa, circular, compartilhada e colaborativa para compor a fundamentação teórica; 2) Ler os dados encontrados; 3) Descrever a compreensão dos conceitos destas áreas e como estão relacionados.

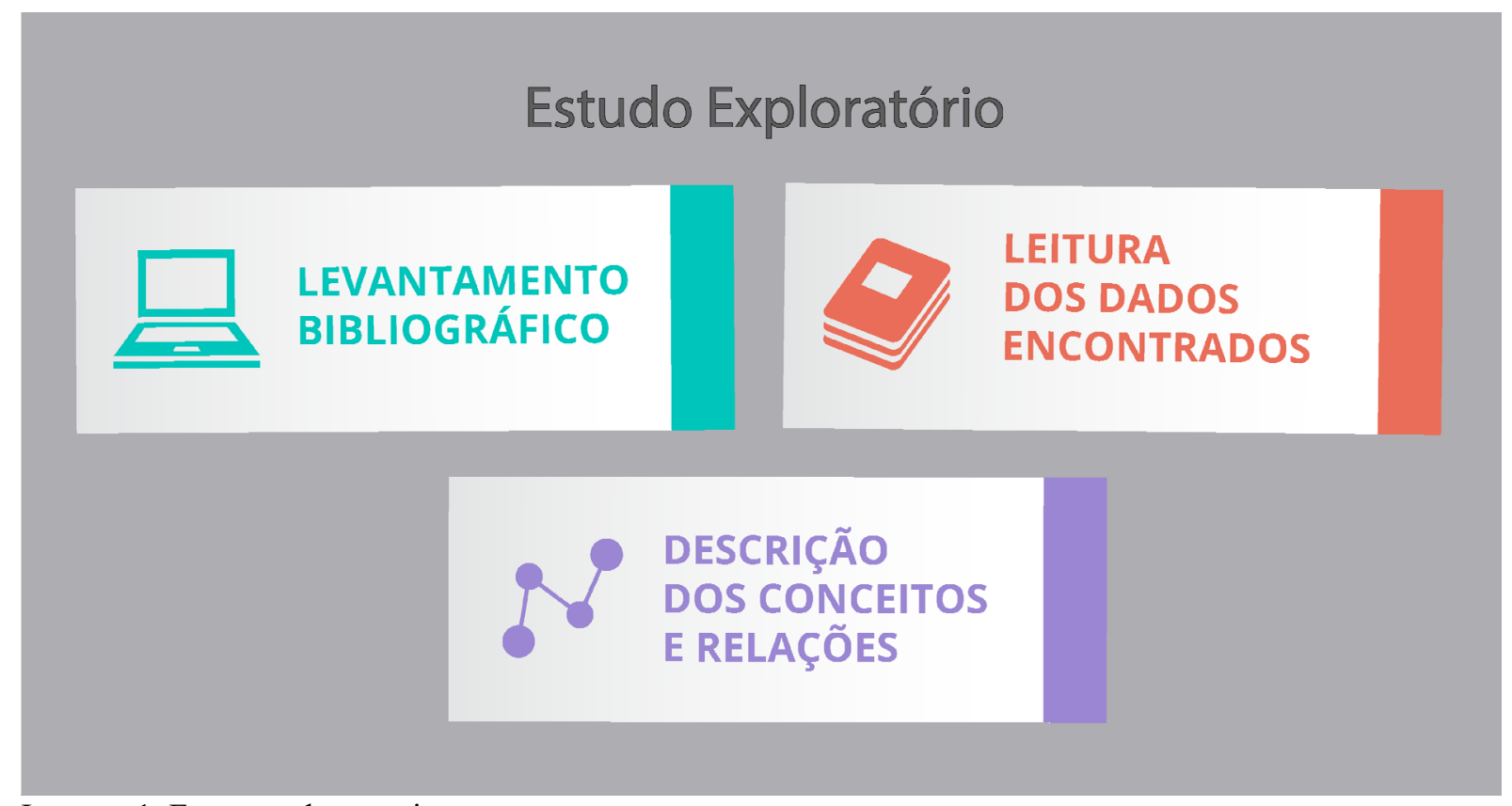

Imagem 1. Estrutura da pesquisa.

Fonte: Elaborado pelos autores. 
Esta pesquisa classifica-se como qualitativa, exploratória e descritiva (CRESWELL, 2016; GIL, 2010; VIRGILLITO, 2010), já que visa compreender as relações entre essas diversas áreas com a finalidade de apontar futuras pesquisas e reflexões. Segundo os procedimentos metodológicos este estudo é considerado bibliográfico com levantamento de dados secundários (CRESWELL, 2016; GIL, 2010; VIRGILLITO, 2010), por utilizar livros e base de dados eletrônicos (como Google Acadêmico e Repositório UFSC) constituídos por artigos, TCC, teses e dissertações. É importante ressaltar que esta pesquisa está em desenvolvimento e é o início de uma pesquisa acadêmica científica, por isso tem um viés exploratório sem a utilização de critérios e especificações mais precisas. O resultado da pesquisa é apresentado em forma de texto descritivo com o apoio de uma imagem que auxilia na compressão das relações encontradas entre as áreas abordadas. O próximo item aborda o início da discussão, relatando sobre a relação da abordagem sistêmica com o design e a gamificação.

\section{A Abordagem sistêmica do design associada à gamificação}

A abordagem sistêmica transfere o foco dos objetos para os sistemas, levando em consideração todos os processos envolvidos. Em vez de essências e substâncias, a organização; em vez das unidades simples e elementares, as unidades complexas; em vez dos agregados formando corpos, os sistemas de sistemas de sistemas (MORIN, 2005).

A abordagem do design busca a produção de coerência, e tem como critério de sucesso a satisfação da sociedade (BONSIEPE, 2011). Dessa forma, seus resultados podem se caracterizar como uma "inovação sociocultural" [...], que é a percepção sistêmica que caracteriza e estimula a atuação do design na contemporaneidade (KRUCKEN, 2009, p.44). Ou seja, a abordagem visa compreender como cada parte de um estudo se inter-relaciona separadamente dentro de um sistema holístico, a fim de mudar as formas de pensar nos projetos de produtos ou serviços.

O design busca comunicar uma informação por meio de um produto ou serviço, como informa Santos (2000) que propõe uma abordagem na qual o design é considerado como um sistema processador de informações, pois tanto na entrada quanto na saída - de um processo de design - são processadas informações. Sendo assim, o design trata-se de uma atividade criativa cujo objetivo é comunicar uma informação de diferentes formas ou meios, determinando as soluções estruturais e funcionais que fazem de um objeto, ou sistema, uma unidade coerente tanto do ponto de vista do produtor como do usuário, abrangendo todas as características do ambiente humano.

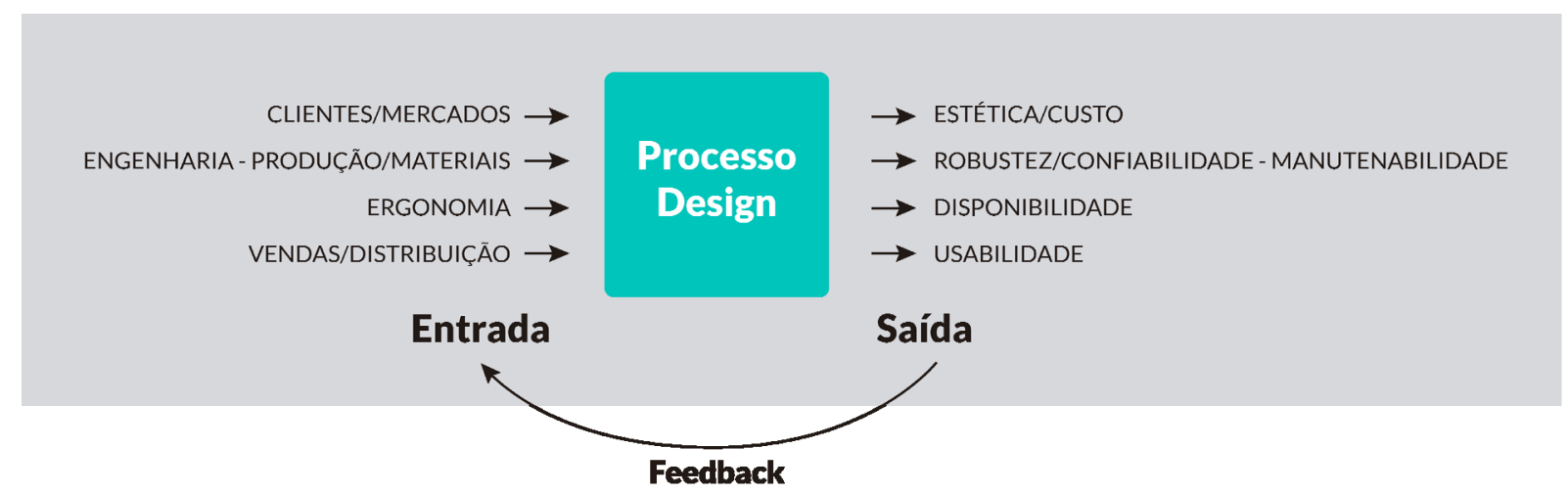

Imagem 2. Abordagem sistêmica do design

Fonte: Santos (2000, p. 24)

O autor informa que tanto na entrada quanto na saída são processadas informações. A imagem 2 mostra que as informações relacionadas: ao mercado e consumidores (Marketing, Sociologia, Psicologia, Antropologia, Economia) resultam na estética (bonito ou feio) e no custo (caro ou barato); as especificações técnicas (Engenharia, Produção, Design Industrial, Materiais, Ergonomia) resultam na robustez, confiabilidade (frágil ou durável), na manutenabilidade (fácil de manter) e na disponibilidade (fácil de encontrar); e as estratégicas (Vendas e Distribuição) resultam na usabilidade (fácil de usar). 
Com isso, é perceptível que o resultado do processo de design não é o produto ou serviço, e sim mais informações "que irão identificar determinado produto ou serviço de um empreendimento no mercado, posicionando-o com relação a concorrentes e consumidores" (SANTOS, 2000, p.23). Além disso, se percebe como a abordagem sistêmica se faz presente no design, pois além da entrada, processo e saída da informação, ainda possui o feedback da interação do usuário com o produto ou serviço. Vasconcellos (2013, p.115) informa que a noção de feedback (ou retroação, ou retroalimentação do sistema) "quer dizer que uma parte do efeito (saída ou output) ou do resultado do comportamento ou funcionamento do sistema volta à entrada do sistema como informação (entrada ou input) e vai influir sobre o seu comportamento subsequente".

A gamificação insere-se neste cenário como uma ferramenta, que pode deixar mais dinâmico o processo de compreensão da abordagem sistêmica no contexto do design de serviço voltado para os microempreendedores, podendo gerar capacitação para os colaboradores e proprietários. Para Vianna et al (2013) a gamificação é a tendência de empregar mecânicas de games para situações que não são de entretenimento, como para as áreas de inovação, marketing, treinamento e desempenho de funcionários, saúde e mudança social. Cohen (2011) informa que a gamificação não é necessariamente desenvolver um game, mas aplicar as características que tornam os jogos envolventes em produtos e serviços. "O objetivo da aplicação de jogos no contexto corporativo é: obter alto nível de comprometimento dos funcionários, facilitar a introdução de mudanças na organização e estimular a inovação" (VIANNA et al, 2013, p.7), engajando os funcionários na resolução de problemas (COHEN, 2011) e "buscando mudar o comportamento do indivíduo" (NAVARRO, 2013, p.18).

A gamificação tem sido aplicada "por empresas e entidades de diversos segmentos como alternativas às abordagens tradicionais, sobretudo no que se refere a encorajar pessoas a adotarem determinados comportamentos, a agilizar seus processos de aprendizado ou de treinamento" (VIANNA et al, 2013, p.13). Dessa forma, ela pode ser uma aliada ao treinamento e produtividade, sendo aplicada em várias áreas do conhecimento para explicar e orientar "o modo como a mecânica e dinâmica dos jogos podem estimular o engajamento das pessoas no desenvolvimento de atividades" acadêmicas ou profissionais, através de experiências divertidas (QUADROS, 2015, p.1).

De acordo com McGonigal (2012), os jogos, por envolverem conteúdos sérios, concentram nossa atenção nos problemas reais e urgentes - como os científicos, sociais, econômicos e ambientais - que temos a nossa frente, sendo embutidos dentro dos jogos. Com eles é possível inventar soluções para alguns desafios humanos. Portanto, hoje os jogos são feitos para mudar o mundo, solucionar problemas reais e orientar ação coletiva real, contribuindo significativamente para o design. A próxima seção relata o contexto dos serviços de microempreendedores onde a abordagem sistêmica associada à gamificação pode ser inserida.

\section{O Design de serviço}

Dentre as áreas do design está à gestão de design, que promove "o gerenciamento bem-sucedido de pessoas, projetos, processos e procedimentos que estão por trás da criação dos produtos, serviços, ambientes e experiências que fazem parte de nossa vida diária" (BEST, 2012, p. 8). Além disso, segundo Mozota (2001), demonstra como implementar o planejamento de design em uma empresa, afim de ajudá-la a alcançar seus objetivos e melhorar a qualidade de seus produtos, serviços e equipes.

Inserido neste contexto, encontra-se o design de serviço que ajuda a inovar, criar novos, ou aperfeiçoar serviços, tornando-os mais úteis, usáveis e desejáveis para os clientes, e eficiente bem como eficaz para as organizações. É um novo campo holístico, multidisciplinar e integrativo, por conectar as áreas de marketing, design, gestão de empresa e pesquisa de cliente (MORITZ, 2005). Além disso, para a empresa Engine Service Design (2010), o design de serviço projeta melhorias em fatores como a facilidade de usar, satisfação, lealdade e eficiência do serviço ligado a áreas como ambientes, comunicação e produtos - sem esquecer-se das pessoas que entregam o serviço (FRANCISCO, 2016). Complementando essa informação, Stickdorn e Scheneider (2011) destacam cinco princípios para o design de serviço que são: centrado no usuário, cocriativo, sequencial, evidenciado e holístico. 
Para o entendimento do design de serviço, é necessário compreender o que é serviço. Para Kotler (2005), o serviço é qualquer ato ou desempenho que uma parte possa oferecer a outra, que seja essencialmente intangível e não resulte na propriedade de nada, onde a execução de um serviço pode ou não estar ligada a um produto físico.

É complicado testar e avaliar as características de um serviço, já que o mesmo não possui uma forma física, principalmente serviços baseados em complexas interações sociais. Por isso, "as ideias complexas [...] requerem protótipos que possam ser liberados em campo para ver como sobrevivem e se adaptam", que seria a prototipagem de serviço (BROWN, 2010, p.93).

Para Brown (2010) a prototipagem

dá forma a uma ideia, nos permitindo aprender com ela, avaliá-la em relação a outras e melhorá-la. Uma simples estrutura de cenário útil no desenvolvimento de novos serviços é a 'jornada do cliente'. Essa estrutura mapeia os estágios pelos quais um cliente imaginário passa, do início ao final de uma experiência [...] (BROWN, 2010, p.89).

Neste contexto estão os serviços prestados por microempreendedores, entre eles está o turismo rural na agricultura familiar (TRAF) que "é uma modalidade de turismo praticada no meio rural", onde "sua principal característica é a presença dos agricultores familiares no contato direto com os turistas" (TURNES e GUZZATTI, 2015, p.34). Em 1999, técnicos e agricultores passaram a se interessar "em conhecer esta forma de produção de alimentos", e como nos municípios não havia restaurantes e hotéis, "vislumbrou-se a oportunidade dos agricultores prestarem serviços de alimentação e hotelaria no meio rural, formando o agroturismo" (TURNES e GUZZATTI, 2015, p.39).

Segundo a Lei n. 11.326/2006, é considerada agricultura familiar àquele que pratica atividades no meio rural, possui área menor a quatro módulos fiscais, mão de obra da própria família, percentual mínimo da renda familiar originada de atividades econômicas do seu estabelecimento, e quando o gerenciamento da propriedade rural é feito pela própria família (BRASIL, 2006).

Além disso, conforme Turnes e Guzzatti (2015), atualmente surgiu o termo slow food (alimentação tranquila) que prega o prazer da gastronomia aliado à preservação da natureza. Zuin e Zuin (2008) informa que consiste em se alimentar utilizando produtos orgânicos, produzidos de forma que respeite o meio ambiente, os produtores e sua cultura.

Portanto, o desenvolvimento sustentável é muito importante para este segmento, já que deve levar em conta as necessidades de todos os cidadãos envolvidos em relação "à dimensão social (educação, saúde, habitação, cultura, lazer), à dimensão econômica (salário, renda, emprego) e à dimensão ambiental (fauna, flora, águas, ar)" (TURNES e GUZZATTI, 2015, p.98; BRASIL, 2006).

Dentro da dimensão econômica existem quatro tipos de economia: a criativa que é o setor econômico formado pelas indústrias criativas, que segundo Howkins (2013) são atividades nas quais a criatividade e o capital intelectual são a matéria-prima para a criação, produção e distribuição de bens e serviço; a circular que se refere a um modelo circular de produção, onde os materiais são devolvidos ao ciclo produtivo através da reutilização, recuperação e reciclagem (LIPOR, 2016); a compartilhada permite que as pessoas mantenham o mesmo estilo de vida, sem precisar adquirir mais, impactando positivamente a sociedade e a sustentabilidade do planeta (TROPOSLAB, 2016); e a colaborativa que surge a partir dos pontos sociais (aumento da população, avanço para a sustentabilidade e desejo de comunidade), econômicos (monetização do estoque em excesso ou ocioso, aumento da flexibilidade financeira, preferência por acesso ao invés de aquisição e abundância de capital de risco) e tecnológicos (beneficiado pelas redes sociais, dispositivos, plataformas móveis e sistemas de pagamento) (KRUPINSK, 2014). A próxima seção visa relatar como se dá a relação das áreas abordadas.

\section{Relações entre as áreas}

Apresenta-se aqui as relações encontradas entre as áreas de abordagem sistêmica, design de serviço, gamificação, gestão de design e a economia dos 4C's, conforme disposta na imagem 3. 


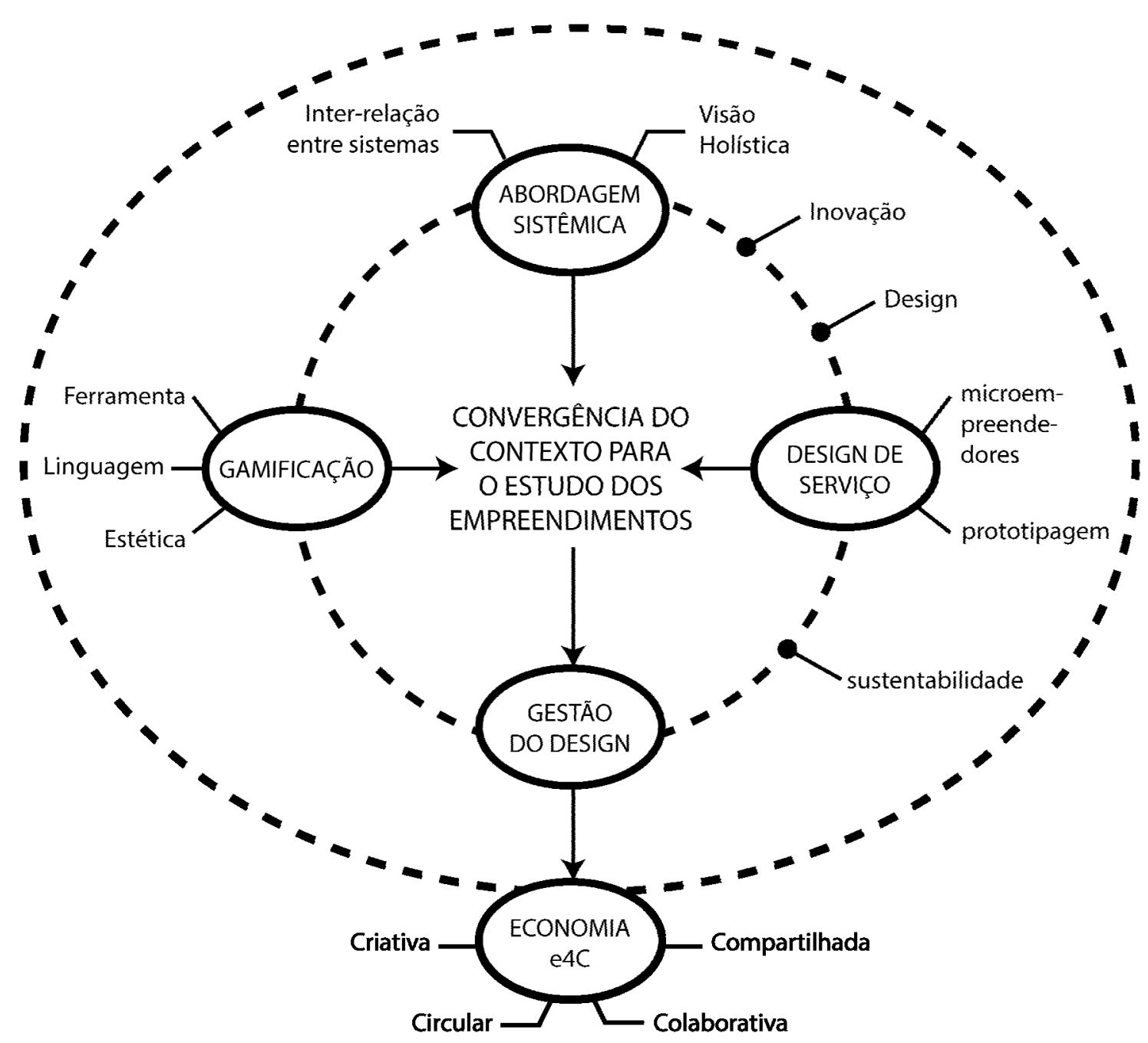

Imagem 3. Relações entre as áreas abordadas.

Fonte: Elaborado pelos autores.

A abordagem sistêmica do design possui uma visão holística ao inter-relacionar os sistemas dos empreendimentos voltados para os serviços, tendo em vista a satisfação da sociedade e de todos os atores envolvidos. O resultado desse processo pode constituir em uma inovação sociocultural, assim afirma os autores Bonsiepe (2011), Morin (2005) e Krucken (2009). Neste contexto estão os serviços prestados por microempreendedores, entre eles está o turismo rural na agricultura familiar (TRAF) e o agroturismo que são as modalidades de turismo praticadas no meio rural e que podem possuir serviços de restaurantes e hotelaria.

A gamificação insere-se nesse cenário como uma ferramenta, que deixará mais dinâmico e envolvente esse processo de compreensão da abordagem sistêmica do design no contexto dos serviços dos microempreendedores, conforme as citações dos autores, expostas anteriormente, Américo, Navari e Belda (2014), Vianna et al (2013), Cohen (2011), Navarro (2013), McGonigal (2012) e Quadros (2015).

O desenvolvimento sustentável é relevante para os serviços de TRAF e agroturismo, pois leva em consideração as necessidades de todos os atores envolvidos nas dimensões social (educação, saúde, habitação, cultura, lazer), econômica (salário, renda, emprego) e ambiental (fauna, flora, águas, ar), como informando por Turnes e Guzzatti (2015). A gestão de design auxilia no gerenciamento desses atores, projetos e processos incluídos no serviço dos microempreendedores, além de ajudar os mesmos a alcançar os objetivos de seus empreendimentos e melhorar a qualidade de seus produtos, serviços e equipes, de acordo com o exposto por Best (2012) e Mozota (2001). Dentro da dimensão econômica do desenvolvimento sustentável existem quatro tipos de economia a: criativa que é o setor econômico formado pelas indústrias criativas; circular composta por um modelo circular de produção; 
compartilhada que permite as pessoas compartilharem informações, serviços e produtos com os cidadãos ao seu redor; e colaborativa que leva em consideração os pontos sociais, econômicos e tecnológicos. A próxima seção conclui as relações encontradas.

\section{Conclusão}

Com isso, conclui-se que a gestão do design - com abordagem sistêmica baseada na produção, serviços e usuários - dos empreendimentos de microempreendedores pode ser aprimorada, por ser uma área em amplo desenvolvimento e possuir grande flexibilidade de oportunidades de negócios como saneamentos, capacitação dos proprietários e colaboradores, atendimento ao cliente, entre outras. Portanto, a abordagem sistêmica associada à gamificação pode ser utilizada como uma ferramenta para compreender o design e o processo de prototipagem de serviços desses empreendimentos, tornando-o mais dinâmico e envolvente.

Por isso, sugere-se para pesquisas futuras: a) o estudo e desenvolvimento de uma abordagem sistêmica gamificada que contribuía para a compreensão sistêmica e dinâmica do design de serviço relacionado com o processo de prototipagem de serviços, inserindo-a no contexto desses microempreendedores; b) e o desenvolvimento de soluções de capacitação e treinamento, por meio da gamificação, para os colaboradores e proprietários dos estabelecimentos empresariais, fazendo-os refletirem sobre a gestão do design de suas empresas e ajudando-os na percepção dos aspectos que podem ser aperfeiçoados.

Essas sugestões de pesquisas são relevantes, pois podem gerar impacto socioeconômico, contribuindo com soluções para aumentar a eficácia dos serviços destes empreendimentos locais, aumentando sua lucratividade e colaborando para o avanço do turismo local.

\section{Systemic approach associated with gamification as a service prototyping tool}

\section{Abstract:}

The design does not restrict only the elaboration and provision of a service, since it has expanded its field of expertise more strategically. For this new look, focus is transferred from the objects to the global study of systems considering all the processes involved. Gamification emerges as a tool to assist in understanding this study, making it more dynamic, entertaining and engaging. Design management seeks to promote better management of people, projects, processes and procedures related to the services, environments and experiences, in addition to targeting a holistic approach. Inserted in this context, it is the service design that helps innovate, create new, or refine services, making them more useful, usable and desirable to customers, efficient and effective for organizations. In the municipality of Chapadão do lager, local establishments need to obey the hygiene and safety norms, to separate and dispose of waste properly and implant systems of visual identity. In the face of the exposed, the questioning arises: how the systemic approach, the gamification and the prototyping of services can be related to the ventures of the micro entrepreneurs? In this way, the research aims to identify the relationship between systemic approach associated with the gamification and prototyping of microentrepreneurial services. However, it is important to clarify that this article seeks to discuss these relationships with secondary data support, consisting of bibliographical references and documents, for the purpose of raising reflections on the subject and providing theoretical basis for scientific academic research. Therefore, research is classified as qualitative, exploratory and descriptive. The results indicate that design management - with a systemic approach based on production, services and user - of micro entrepreneurial enterprises can be enhanced, because it is a broad development area and has great flexibility of business opportunities such as 
sanitation, training, customer service, among others. Furthermore, this article contributes a theoretical discussion on the systemic approach to the gamification and the prototyping of services, which will serve as a basis for the development of a scientific academic research, and to contribute a reflection to new research in this area.

Keywords:

Design management, systemic approach, prototyping services, gamification.

\section{Referências bibliográficas}

AMÉRICO, Marcos; NAVARI, Shelley Costa; BELDA, Francisco Rolfsen. Gamificação: modelagem de conteúdos para programas e aplicativos educativos no ambiente da tv digital interativa, in Revista Ibero-americana de Estudos em Educação, v. 9, n. 4, UNESP. Araraquara, SP: 2014.

BERTALANFFY, Ludwig Von. Teoria geral dos sistemas: fundamentos, desenvolvimento e aplicações, 3. ed., Vozes. Petrópolis, RJ: 2008.

BEST, Kathryn. Fundamentos de gestão do design, Bookman. Porto Alegre: 2012.

BONSIEPE, Gui. Design, Cultura e Sociedade, Blucher. São Paulo: 2011.

BRASIL. Lei Federal n. ${ }^{\circ}$ 11.326, de 24 de julho de 2006. Estabelece as diretrizes para a formulação da Política Nacional da Agricultura Familiar e Empreendimentos Familiares Rurais, in: Diário Oficial da República Federativa do Brasil. Brasília, DF: 2006. Disponível em: <http://www.planalto.gov.br/ccivil_03/_Ato2004-2006/2006/Lei/L11326.htm>. Acesso em: 04 Jul. 2016.

BROWN, Tim. Design thinking: uma metodologia ponderosa para decretar o fim das velhas ideias, Elsevier. Rio de Janeiro: 2010.

COHEN, Aaron M. The gamification of education, in: Futurist, v. 45, n. 5, p. 16-17. Washington: Sep/Oct 2011.

CRESWELL, John W. Projeto de pesquisa: métodos qualitativo, quantitativo e misto, SAGE. Porto Alegre: 2010.

FIGUEIREDO, Luiz Fernando Gonçalves de; MERINO, Eugenio; MUNIZ, Marco Ogê; MERINO, Giselle. Aplicação do design em casos de Inovação social do Estado de Santa Catarina, Brasil, in: V CIPED. Bauru, SP: 10-12 Out 2009.

FRANCISCO, Pedro Henrique Dier. Avaliação estética de protótipos no design de serviço. Dissertação (Mestrado em Design), Setor de Artes, Comunicação e Design, Universidade Federal do Paraná. Curitiba: 2016.

GIL, Antonio C. Como elaborar projetos de pesquisa, Atlas. São Paulo: 2010.

HOWKINS, John. The creative economy: how people make money from ideas, 2 . ed., Penguin. United Kingdom: 2013.

KOTLER, Philip. Administração de Marketing, Prentice Hall. São Paulo: 2005.

KRUCKEN, L. Design e território: valorização de identidades e produtos locais, 1. ed., v. 1., Nobel. São Paulo: 2009.

KRUPINSK, Cássio. Entendendo a economia colaborativa e compartilhada. 2014. Disponível em: $\quad<$ http://ecommercenews.com.br/artigos/cases/entendendo-a-economia-colaborativa-ecompartilhada>. Acesso em: 14 Ago. 2016.

LIPOR. Economia Circular: conceito e benefício. 2016. Disponível em: <http://www.lipor.pt/pt/residuos-conceitos-fundamentais/economia-circular-conceito-e-beneficio/>. Acesso em: 14 Ago. 2016. 
MARSHALL JUNIOR, Isnard; ROCHA, Alexandre Varanda; MOTA, Edmarson Bacelar. Gestão da qualidade e processos, FGV. Rio de Janeiro, RJ: 2012.

MCGONIGAL, Jane. A realidade em jogo, BestSeller. Rio de Janeiro: 2012.

MORIN, Edgar. 0 método 1: a natureza da natureza, Sulina. Porto Alegre: 2005.

MORITZ, Stefan. Service Design: practical access to an evolving fiel, Köln International School of Design. London: 2005.

MOZOTA, Brigitte Borja de. Gestão do design: Usando o design para construir o valor de marca e inovação corporativa, Bookman. Porto Alegre: 2011.

LAURO, Aline Bertolini; HOFFMANN; FIGUEIREDO, Luiz Fernando Gonçalves de. Design para inovação social sob a ótica ambiental: um estudo de caso em Chapadão do Lageado, in: Anais do 40 $^{\circ}$ Simpósio Paranaense de Design Sutentável (SPDS), v. 1, p. 37-49, UFPR. Curitiba: 2012.

NAVARRO, Gabrielle. Gamificação: a transformação do conceito do termo jogo no contexto da pósmodernidade, Biblioteca Latino-Americana de Cultura e Comunicação, v. 1, n. 1, p. 1-26. São Paulo: 2013. Disponível em: <http://200.144.182.130/celacc/sites/default/files/media/tcc/578-1589-1PB.pdf>. Acesso em: 16 Jul. 2016.

QUADROS, Gerson Bruno Forgiarini de. Construindo o estado da arte da gamificação, In: Anais do Encontro Virtual de Documentação em Software Livre e Congresso Internacional de Linguagem e Tecnologia Online. Belo Horizonte: 2015. Disponível em: < http://www.periodicos.letras.ufmg.br/index.php/anais_linguagem_tecnologia/article/view/8446>.

Acesso em: 16 Jul. 2016.

SANTOS, Flávio Anthero dos. O design como diferencial competitivo: o processo de design desenvolvido sob o enfoque da qualidade e da gestão estratégica, Editora da Univali, 2. ed. Itajaí: 2000.

STICKDORN, Marc; SCHENEIDER, Jakob. This is service design thinking: basics, tools, cases, Wiley. Amsterdan: 2012.

TROPOSLAB. O que é meu é seu: economia do compartilhamento. 2016. Disponível em: <http://www.troposlab.com/blog/o-que-e-meu-e-seu-economia-do-compartilhamento/>. Acesso em: 14 Ago. 2016.

TURNES, Valério Alécio; GUZZATTI, Thaise Costa. Turismo rural na agricultura familiar: conceitos e práticas, Imaginar o Brasil. Florianópolis: 2015.

VASCONCELLOS, Maria José Esteves de. Pensamento sistêmico: o novo paradigma da ciência, Papírus, 10. ed. Campinas, SP: 2013.

VIANNA, Ysmar; VIANNA, Maurício; MEDINA, Bruno; SAMARA; Tanaka. Gamification, inc: como reinventar empresas a partir de jogos, 1. ed., MJV Press. Rio de Janeiro: 2013.

VIRGILLITO, Salvatore Benito. Pesquisa de marketing: uma abordagem quantitativa e qualitativa, Saraiva. São Paulo, SP: 2010.

ZUIN, Luís Fernando Soares; ZUIN, Poliana Bruno. Produção de alimentos tradicionais contribuindo para o desenvolvimento local/regional e dos pequenos produtores rurais, Revista Brasileira de Gestão e Desenvolvimento Regional, v. 4, n. 1, FURB. Blumenau: 2008. 